\title{
Consumerist Approach to Sexuality in A World of Dynamism: Hanif Kureishi's The Nothing
}

Tarik Ziyad Gulcu

Lecturer, School of Foreign Languages, Ankara University, Turkey

\section{ARTICLE INFO}

Keywords:

British novel

Globalisation

Transformation

Interpersonal relations

Temporary

\begin{abstract}
As one of the major phenomena in the contemporary global context, consumerism has been shaping lifestyles in different aspects. Signifying the demand for the consumption of the properties that are produced and accessed quickly, consumerism has not only shaped the tendencies for the consumption of products, but it has also had impact on the approach to interpersonal relations in cultural, social and individual areas. In contemporary British fiction, Kamila Shamsie focuses on the disillusionment of the immigrants with their hopes for a civilised life due to their consideration as "outsiders" and she views this as an embodiment of the consumption of their dreams for the future in Home Fire (2017). Zadie Smith reflects the consumerist approach to the relations among family members in On Beauty (2005) with reference to Howard Belsey's affair with Victoria as a signification of the quest for his new self and his failed efforts for the reconciliation with his family. However, in The Nothing (2017), Kureishi reveals that consumerism also leads to temporary sexual relations among the people. Focusing on Zee's affair with Eddie instead of her husband, Waldo because of his old age and infertility, Eddie's sexual relations with Patricia and Sarah, Kureishi's The Nothing invites reading in relation to its focus on the short-term sexual relations among the people as an embodiment of the consumerist approach to interpersonal relations and an inevitable quest for a new personal identity within the dynamism of the contemporary world.
\end{abstract}

\section{Introduction}

\section{Consumerism as the Dominant Ideology of the Contemporary World}

From the late twentieth century onwards, globalisation as a major phenomenon has been shaping the lifestyles all over the world. In fact, globalisation has turned out to characterise the contemporary way of life. In Christian Karner and Alan Aldridge (2004)'s words,

\begin{abstract}
"life in the last quarter of the twentieth century underwent a series of profound transformations involving the emergence of a novel economic and cultural logic based on international networks of interrelated and adaptive modes of activity, cooperation and communication. [...]. The global integration of financial markets, the key role of multinational companies (and their complex networks of economic cooperation) in the globalisation of markets for goods and services, as well as fundamentally altered experiences of space and time are all defining features of a new and global social (dis)order. (p. 9-10)"
\end{abstract}

The establishment of networks on international scale brings a high flow of change in the contemporary context. David Held (2004)'s following argument epitomises the interrelatedness of interactions in the global area: "Drugs, crime, sex, war, protest

\footnotetext{
* Corresponding Author E-Mail Address: tarikzgulcu@yahoo.com 
movements, terrorism, disease, people, ideas, images, news, information, entertainment, pollution. Goods and money [...] now all travel the globe" (p. 6). The travel of ideologies, social movements, as well as the products all over the world signifies the inevitability of international networks in the contemporary context. Hence, in Peter Beyer (1994)'s words, "we [...] live in a globalising social reality, one in which previously effective barriers to communication no longer exist" (p. 1).

While globalisation arguably contributes to the establishment of harmony and dialogue among the countries with different cultural values, it may also bring negative consequences in relation to both social and cultural relations in the global context. Stuart Hall (1992)'s following arguments account for the emergence of socio-cultural monopoly rather than harmony in the contemporary global context: "In the latest form of globalisation, it is still the images, artefacts and identities of Western modernity produced by the cultural industries of 'Western' societies [...] which dominate the global networks" (pp. 304-305). The dominance of Western mode of production establishes the basis of the consumption of Western products. In socio-economic context, capitalism in particular contributes to the dominance of Western products all over the world. The demand for those products somehow shows increase as they are consumed more and more in the global area. Thus, in the process of globalisation, the demand for and consumption of Western products inevitably turns out to shape the views of life in individual, social and global terms. In Akbar S. Ahmad and Hastings Donnan (1994)'s words, the capitalist worldview "promotes a culture based on youth, change and consumerism" (p. 12). The constant flux as an inevitable by-product of capitalism in the contemporary context somehow makes it impossible to maintain a certain outlook on life in individual and social senses under the contemporary globalising world circumstances. At this point, consumerism represents the major ideology in the twenty-first century global area because of its domineering impact on the lives and worldviews of individuals and societies. George S. Day and David A. Aaker (1970)'s following description reflects the basis of consumerism in general sense:

\footnotetext{
"The most common understanding of consumerism is in reference to the widening range of activities of government, business, and independent organisations that are designed to protect individuals from practices [...] that infringe upon their rights as consumers. This view of consumerism emphasises the direct relationship between the individual consumer and the business firm. (p. 13)"
}

The increasing variety of international business firms and their direct relation with the consumers enable people to gain easy and quick access to the products all over the world. The opportunity to access products directly and quickly somehow motivates people to increase their tendency to the consumption of more goods. The increasing tendency to consume more products arguably accounts for a new outlook on life based on capitalist ideals. Hence, the selection of products and their rapid consumption lead to the emergence of the impact of new products on the worldviews and lifestyles of the people in the global area. Feng Lu (2010)'s following arguments reveal the extent to which consumption tendencies shape the lifestyles and views of life of the people: "The reason why people purchase commodities is not only the use value of goods but also their symbolic worth" (p. 92). The symbolic worth of consuming commodities is related to the association of the individual self with consumption. In line with this argument, Feng Lu (2010) explains the basis of the individual identity on the consumption tendencies in contemporary context in the following words:

"People's mass consumption driven by the consumption society in nature is stimulated by the capital owners of the society. Media offers emotional words and luring pictures to inspire us to 
consume every day. [...]. The biggest beneficiaries from our consumption are those capital owners. The more we buy, the more they profit. [...]. [As] people targeting at making money in their lives become the backbone, the lifestyle of capital owners is the most proper and admiring one. [...]. The Gospel preached by consumerism is that the more you gain and consume, the happier you are. (p. 92)"

In the contemporary circumstances, the dependence of happiness on the consumption of commodities is arguably a problematic issue because contemporary people turn out to get alienated from the social values and ideals on which they base their lives. Accordingly, in Christian Karner and Alan Aldridge (2004)'s words, “consumerism has arguably colonised religious beliefs and identities" (p. 25). Hence, consumerism not only leads to the rapid consumption of commodities and a demand for their renewals, but it also causes the consumption of social values on which individual identities are based. In Paul Kennedy (2001)'s words, “cultural experiences of all kinds - abstract knowledge, aesthetic preferences in everything from cuisine and music to designer goods [...], religious beliefs and so on exhibit a growing capacity to break loose from their original moorings in particular societies" (p. 11). Because contemporary lifestyle is based on consumerism and a constant process of flux in the global area, it somehow becomes difficult or even impossible to maintain a steady identity based on a specific set of cultural and social values. This situation inevitably leads to a quest for a new life based on a new identity in individual and social terms.

\section{Consumerism in Contemporary British Fiction}

Authors of contemporary fiction somehow reflect their sensitivities to the quest for a new life based on a new identity in the twenty first century context. In their works, they emphasise this quest of contemporary man in relation to the inevitability of interconnectedness among the communities from peculiar identities and its effects on the intercultural relations in the global context. Daniel O'Gormann (2013) explains this problematic issue of the contemporary period with reference to the issue of migration:

\footnotetext{
"Migration, and the crossing of the lines that it entails, has attained a new, post-9/11 level of complexity: the postmodern, 'post-Historical' 'Western' liberal democracy of the 1990s has itself been forced to step across the line between 'History' and historicity, to paradoxically migrate into a state of perpetual migration, a passé-partout in-between space that problematizes the very idea of space itself. This results in a profound sense of disorientation, and, in turn, existential selfquestioning. (p. 93)"
}

Elleke Boehmer (2005) deals with the reasons for migration in the following words: "The late twentieth century witnessed demographic shifts on an unprecedented scale, impelled by many different forces: anti-imperialist conflict, the claims of rival nationalisms, economic hardship, famine, state repression, the search for new opportunities" (p. 226). Hence, migration can be considered as an embodiment of contemporary man's quest for a new identity and a new way of life. The consideration of the immigrants as "outsiders" in the host country somehow leads to the emergence of disorientation and self-questioning among the major problems in immigrant communities. So, considering this situation in relation to the term "consumerism", the expectations of the immigrants for their better life standards in the Western countries are inevitably consumed by the members of the host society. Kamila Shamsie's Home Fire is arguably an epitome regarding the disorientation of the immigrants because of their consideration as "outsiders" despite their alienation from their original identities. In the work, Shamsie deals with the inevitability of the increasingly biased approach of the Western countries to the immigrants, particularly due to the association of the people from Oriental countries with terrorism in post-9/11 period with reference to the Home Secretary Lone Wolfe's opposition to his son Eamon's love for Aneeka, depicted as a Pakistani character. 
Lone Wolfe's following dialogue with his son embodies the inevitable disorientation and self-questioning of the immigrants because of the host country's consumption of their expectations for a life in high and modern standards:

\footnotetext{
'You will have no more contact with this girl. I am setting up a security detail for you.'

'Dad! Look, just meet her. All right? I'll bring her over. Tonight, this evening, and ... what's so funny?'

'All this security around the house, and the nexus of $[\ldots]$ Islamic State is just going to waltz in on the arm of my son.'

'Don't you ever refer to her in that way again. She's the woman I am going to marry.'

Nothing moved in his father's face. 'Stay here.'

'Or what, you'll arrest me?' But the Home Secretary was gone before the end of the sentence, door slamming behind him. (Shamsie, 2017, p. 109)
}

The increasing sense of insecurity particularly as a result of 9/11 events has had a negative impact on the outlook on the immigrants in the host culture. Despite their expectations for leading a life in prosperity and civilisation, their consideration as "outsiders" by the people in the host countries because of security concerns embodies the immigrants' disillusionment with their future lives. This situation explains the consumerist approach to immigrants' hopes and dreams for better and higher life standards.

Similar to the immigrants' case in cultural context, contemporary people also get alienated from the traditional social institutions, particularly family. The relations among the family members are consumed because they do not maintain their relations in a steady manner as an inevitable product of constant flux and dynamism of the contemporary world. Zadie Smith's on Beauty is an epitome of the consumed family relations in the twenty first century context. Smith's following words as the narrator of the work are arguably an explanation for the protagonist Howard Belsey's quest for a new life and identity: "He saw himself [...] as a man hustled by circumstances into spaces that he rejected politically, personally, aesthetically, as a concession to his family. One among many concessions" (Smith, 2005, pp. 33-34). Howard's failure in the integration with the social context somehow leads to his alienation from social values and institutions. His deep knowledge of a wide variety of ideologies as an academic cannot contribute to his appreciation of the real-life circumstances. Thus, antithetical to his family, he does not find a sense of belonging to the social life in the contemporary context. The narrator specifies Howard's quest for a new self in relation to his consumption of family relations in the following words: "Almost all the men Howard knew were already divorced, had begun again with new women; they told him things like 'you get to the end of a woman' [...] Had he finally got to the end of Kiki?" (Smith, 2005, p. 110). Howard's impression about marriage and family relations is somehow shaped in accordance with the men with whom he interacts in daily life. The common practice of ending marriages and starting a new relation with a new woman embodies the alienation from family as a traditional social institution. Thus, his affair with Victoria, the daughter of Monty Kipps who is depicted as a rival academic to Howard in the novel, represents both his consumerist approach to his family relations and his quest for a new self:

\footnotetext{
She pulled him on the bed. Before he had a chance to consider removing her shirt she had already done the job for him. And then came more of this purring and moaning, although his hands had not yet reached her breasts, and he was presently struggling, at the other end of the bed, to kick one shoe off by means of attacking it with the other.

'Fuck me,' said Victoria, once, and then again, and then again.

'Put it in me,' she said.

OK, then. Howard took hold of his cock and began the breach. (Smith, 2005, pp. 315-317)
} 
Howard's failure in finding his new identity by means of his affair with Victoria leads him to return to his family relations. However, Kiki's following response to him indicates the inevitability of change in the dynamism of the globalising world: "Howard, I love you. But I am not just interested in watching this second adolescence. I had my adolescence. I can't go through yours again"” (Smith, 2005, p. 398). Howard's efforts for re-establishing a harmonious relation with his family, especially his wife, cannot be realised because while he alienates himself from his original self and has an affair with Victoria as a means of his discovery of a new personal identity, Kiki somehow inevitably cannot remain steady and hence she also shows changes in terms of her approach to the concepts of "family" and "husband". Thus, similar to Howard, Kiki also reflects her individuality instead of showing her attachment to family as a traditional social institution. Hence, consumerist approach is not only seen in Howard, but his wife as well and this viewpoint somehow makes the reconciliation in Belsey family impossible.

Along with its cultural and social aspects, the effects of consumerist approach in the contemporary context are also observed in individual sense. At this point, Zadie Smith's Swing Time is arguably an epitome of the reflection of consumerism about the friendship of the two girls in the novel, i.e., the narrator herself and her friend Tracey with regard to the inevitable change in their views of life. Early in the novel, the narrator dreams to have an independent individual identity in freedom just as Tracey has:

\begin{abstract}
"She kept a key in her pencil case, let herself in, went straight to the sofa and began watching the Australian soaps until the British ones started, a process which began at four p.m. and ended when credits ran on Coronation Street. Somewhere in between she either got her own tea or her mother arrived with takeaway and joined her on the sofa. I dreamt of freedom like hers. (Smith, 2017, p. 64)"
\end{abstract}

Tracey's occupation of a key in her case, her arrival to home back according to her own free will and preparation of her food and drink not by parental help but by herself signify her individual choices. However, unlike Tracey's individualism, the narrator's tendency to the attachment to traditional social system and hence her failure in claiming her individual preferences is embodied in the following words: "When I got home either my mother or my father wanted to know 'what had happened at school today', [...] I wouldn't be let alone until I told tem something, and so, naturally, I began lying to them" (Smith, 2017, p. 64). In the novel, the narrator's encouragement by Aimee, her patron in the work, to discover her self embodies the change in both the narrator and Tracey's views of life and opinions about each other. Later in the work, while the narrator achieves the discovery of her female identity, Tracey's loss of her individuality leads to the termination of their friendship, as epitomised in the following conversation between the two characters:

\footnotetext{
"There can't be no understanding between you and me any more! You're part of a different system now. [...]"

[...] What are you talking about? Trace, you're a grown woman now, you've got three beautiful kids, you really need to get a grip on this kind of delusional -"

You can call it by any fancy name you like, love: there's a system, and you and your fucking mother are a part of it." (Smith, 2017, pp. 405-406)
}

While they are depicted as intimate friends, the change in the narrator and Tracey's approaches to life and humankind somehow influences their relation with each other. Because contemporary period is characterised by "flux", it is somehow impossible to maintain friendships for very long periods. The dynamism and constant change inevitably bring with its temporary relations that are not based on the established social codes and ideals. 
As a writer sensitive to the temporariness of interpersonal relations in contemporary context, Salman Rushdie's following words as the narrator of Two Years, Eight Months and TwentyEight Nights can be viewed as an explanation for the prevalence of the consumerist approach not only to commodities but also the relations with the different members of the societies in daily life:

\footnotetext{
"In the world of literature there was a noticeable separation of the writers from their subjects. Scientists reported the separation of causes and effects. It became impossible to compile new editions of dictionaries on account of the separation of words and meanings. Economists noted the growing separation of the rich from the poor. The divorce courts experienced a sharp increase in business owing to a spate of marital separations. Old friendships came abruptly to an end. The separation plague spread rapidly across the world. (Rushdie, 2015, p. 161)"
}

"Change" is the word that best characterises contemporary lifestyle. The dynamism of the contemporary world makes it impossible to maintain a steady view of life and approach to people and life in general. Inevitably, individual and social ideals are not valued as before. As a direct result of the loss of attachment to the traditional social values, the relations among friends, family members, husbands and wives and people from different social strata somehow lose their meanings. The loss in the attribution of meaning to interpersonal relations in various aspects of daily life leads to the establishment of temporary and changeable relations. The quick and easy termination of interpersonal relations establishes the basis for the consumption of human relations like the commodities and hence the consumerist approach to humankind and personal interactions in the social area in the contemporary context.

\section{Inevitably Consumerist: Sexuality in Hanif Kureishi's The Nothing}

Similar to his contemporaries like Kamila Shamsie, Salman Rushdie and Zadie Smith, Hanif Kureishi also reflects his sensitivity to the effects of consumerism as a dominant view of life on individual and social areas in the twenty first century context. Though famous for his works, in particular The Buddha of Suburbia, on intercultural relations, migration, biases against the immigrants and ambivalence as its by-product, Kureishi also focuses on the temporariness of interpersonal relations in different dimensions of daily life. At this point, his approach to humankind and life is worth mentioning to appreciate his outlook on the effects of consumerism on the people in the contemporary context.

Kureishi's following words in Ray Deonandan's interview with him arguably signify his approach valuing humankind as a whole: "I am an observer, a humanist; I'm interested in the way men and women relate to each other" (The Podium, 2002). Putting emphasis on the significance of human relations, Kureishi explains the characteristics of an ideal individual. In his short story "Lately" included in his short story collection Love in a Blue Time (1997), the following dialogue between Vance and Bodger epitomise these traits from Kureishi's perspective:

\footnotetext{
"Bodger hurried in. 'The weather will spoil everything anyway.' He sat down. We have to care for one another. Yes! Otherwise, we lose our humanity.'

Vance went on, 'We have the weak - people like Rocco - dominating the strong with their whingeing. They want others to do everything for them. but they will deplete our strength and drag us down. Selfishness, wanting something for oneself, is the law of reality. But if I benefit, others will benefit.' (Kureishi, 1997b, p. 174)"
}

Because of his attribution of significance to the interpersonal relations, Kureishi puts emphasis on the importance of people's sensitivity to each other in the social area. For Kureishi, it is a humane characteristic to get sensitive and respectful to the individuals in the 
daily life. Sensitivity to each other, communication with different people as well as sharing the emotions and ideas in the social context may inhibit the emergence of selfishness as not only an individual but also a social problem. Thus, Kureishi's following words as the narrator in his short story "The Umbrella" in the collection Midnight All Day can be considered as an explanation as to how to achieve and maintain humane essence of mankind in contemporary context: "The world would be a better place if people considered their actions" (Kureishi, 1999, p. 342).

Despite his humanistic outlook on mankind and life, Kureishi somehow takes the dominance of consumerism in the contemporary social life for granted. The narrator's following depiction about Baxter and his wife in "The Flies" in the short story collection Love in a Blue Time epitomise Kureishi's emphasis on the inevitability of consumerism as a dominant view of life in the contemporary context:

\footnotetext{
"He is unemployed and most of their money has been spent on rent, bills, debts and the child. If he were to put it plainly, he'd say that they can hardly taste their food; they can't even watch TV for long. [...]. Before the birth, they'd been together for a few months, and then serious lovers for a year. Since the child, their arguments have increased, which Baxter imagines is natural as so much has happened to them. But their disagreements have taken on a new tone. There was a moment recently when they looked at one another and said, simultaneously, that they wished they had never met. (Kureishi, 1997c, p. 183)"
}

Considering "flux" as the major characteristic of contemporary lifestyle, the change in Baxter's life because of his unemployment and the economic hardships he starts to experience has somehow affected his relation with his wife negatively. The transformation in their lives leads to the change in their approach to the love they have for each other. The loss of meaning in the term "love" in both Baxter and his wife's mind accounts for the inevitable transformation in their relations with each other and their family life. The constant dynamism of the contemporary world inevitably brings rapid changes in life circumstances, interpersonal relations, family life as well as the meanings attributed to traditional social system. Hence, the change in Baxter and his wife's approach to "love" as a concept accounts for the temporariness of their emotions for each other. Thus, it is not wrong to argue that as a major phenomenon in the contemporary context, consumerism shapes even the people's feelings about each other.

While consumerism leads to the change in interpersonal relations and lifestyles, this transformation it causes establishes the basis of contemporary individual's quest for a new self. Consumerism leads to this quest not only in the social and cultural areas, but also in terms of sexuality in contemporary context. In Kureishi's words in Ray Deonandan's interview with him, "Sexuality is at the centre of our lives. It's who we are" (The Podium, 2002)). Hence, in line with Kureishi's argument, consumerism leads to a quest for a new self in terms of sexuality as well, in addition to cultural and social identity.

Among his works, Kureishi's The Nothing epitomises the consumerist approach to interpersonal relations and the quest for a new self in sexual sense as its by-product in the twenty-first century context. The novel deals with the relation between a husband and a wife, Waldo and Zee, as well as the transformation in their relation and the approaches to each other. Early in the novel, Waldo, the narrator of the work as well, reflects his family as a motive for the exploration of his self in the following words:

"I wanted to see, at last, how close I could get to a woman. How close I could get to another human, while we remained separate human beings. I wanted to lose myself and become utterly dependent. I wanted her to change me. [...]. Zee and I married, to show our seriousness. I wanted to be a husband, but had to become a stepfather too. [...]. The achievement of loving a woman meant more to me than anything else. At last we settled the kids in American universities, for 
which I paid. [...]. Jasmine works in hotels. Samreen reminded me of myself [...]. In her late twenties she gained momentum with a sudden ambition to become a doctor. She sat down and studied. She became a dedicated gynaecologist, working with poor women in Los Angeles. We have come to like one another. Both girls have taken my name and they can make me laugh. I am proud to be head of this family. (Kureishi, 2017a, pp. 31-33)"

Waldo views the establishment of family as a means of his self-discovery in relation to his individual identity. His demand to be a dependent person and his pride in becoming the head of family because of the two daughters' positions as a hotel staff and gynaecologist represent his attachment to family as a traditional social institution. Similar to his situation, the daughters' positions embody their integration with the established system in the social area. Nel Noddings (1989)'s following words describe women's roles in the family as a fundamental part of traditional social system:

\footnotetext{
"Woman has been associated in a stereotypical way with both good and evil. As an 'angel in the house', woman has been credited with natural goodness, an innate allegiance to 'a law of kindness'. But this same description extols her as an infantile, weak, and mindless - a creature in constant need of male supervision and protection. (p. 59)"
}

In line with Noddings's arguments, Waldo's following words as the narrator arguably explain his favour for the patriarchal system as the dominant viewpoint shaping the established social roles: "Zee has always been devoted. She is the woman I always wanted. She gave up her country, her relatives, her husband for me. Once she said she'd love me even if I didn't have a penis" (Kureishi, 2017a, p. 17).

Considering the inevitability of change in the social area in the contemporary world, the devotion and loyalty Zee shows to Waldo turns out to become temporary. The narrator's following arguments can be considered as an explanation for the termination of family unity between Waldo and Zee: "Ethics are a pathological violence and the good an obstacle. [...]. Progress is the overcoming of taboos" (Kureishi, 2017a, pp. 18-19). The consideration of moral values as "disease" and the dependence of progress on the opposition to ethical restrictions embody contemporary humankind's alienation from the established social system and its values. Particularly, the impact of consumerism on the temporariness of human relations and the loss of attachment to traditional merits somehow inevitably bring a new way of life in the twenty-first century context. At this point, Zee does not continue to show her devotion to Waldo because of the physical changes in him:

\footnotetext{
"In the last ten years I declined and became weak. Cocaine had done for my heart. I have a stent. I also have most illnesses: diabetes, prostrate cancer, an ulcer, an early MS, constipation, diarrhoea and only one good hip, a cough, phobias, addictions, obsessions and hypochondria. Otherwise I am in great shape. Zee takes care of me. It is her responsibility, and love. (Kureishi, 2017a, pp. 33-34)"
}

Whereas Waldo views Zee's care for his illnesses as fundamental parts of her domestic responsibilities in patriarchal sense, her experience of no sexual affair with him reflects the loss of meaning of "husband" and "wife" in Zee's mind in terms of sexuality: "There's no life in her life, and she hasn't had sex for at least seven years. I cannot satisfy her in any way. She masturbated, I suspect, to romantic scenes in front of the TV" (Kureishi, 2017a, p. 17). Among Kureishi's contemporaries, Zadie Smith as the narrator of $N W$ focuses on masturbation as a way to discover the female sexual self in the following words:

\footnotetext{
"A vaginal orgasm can be provoked $[\ldots]$ by simply moving one's pelvis forward and backwards [...] There seems to be a small piece of flesh [...] halfway up the wall of vaginal canal on the side nearest your belly button [...] whether this is what is meant by the phrase ' $G$-spot', and whether it
} 
is the cause of the almost unbearably pleasurable sensation, Keisha Blake could not verify one way or another. (Smith, 2013, p. 190)"

In the patriarchal discourse, women are expected to have a sexual affair only with their husbands to maintain and reinforce family as a fundamental element of the traditional social system. Thus, in Diane Mason (2008)'s words, according to the patriarchal system, "female masturbation [is] a condition described [...] as a 'plague', a 'contamination'” (p. 29). Hence, Keisha Blake's attempts to discover her genitals and learn about female orgasm are an embodiment of her quest for her self in sexual sense. Similar to Keisha's case, Zee's masturbation while watching TV is a representation of her efforts for the discovery of her new individuality independent from her husband in sexual context. Although it is antithetical to Waldo's viewpoint idealising the family as the signification of the established social structure, Zee's masturbation represents her efforts to discover her individual sexual identity as well as her alienation from her husband, Waldo. While exploring her self by means of masturbation, the transformation in Zee's preference for a love affair with Eddie signifies not only the dynamism but also the temporariness of sexual relations among people as a byproduct of consumerism as a dominant view of life in the contemporary context. Waldo as the narrator in the novel puts emphasis on the constant transformation in sexual relations among the people in the following words:

\footnotetext{
"Looking keeps the world marvellous. And sex, even when I am immobile, indeed almost a vegetable in a wheelchair, can be intense. I recall the taste and smell of her, my last and only love Zee, the one whose body I enjoyed more than any other. I recall how shameless she became for me, and the games we played.

Now she is opening her mouth for him. Her fingers tug at his cock. Perhaps he is pulling her hair, as she likes it. (Kureishi, 2017a, p. 5)"
}

Kureishi's short story "Nightlight" focuses on a sexual relation between a man and a woman. In the story, the two characters meet each other every Wednesday. However, the woman's absence in one of these meetings accounts for the temporariness of sexual relations among the people in contemporary period. The narrator's following depiction can be considered as an epitome of the inevitably temporary interactions among the individuals in sexual terms:

\footnotetext{
"One Wednesday the cab doesn't draw up. He stands at the window in his dressing gown and slippers for three hours, feeling in the first hour like Casanova, in the second like a child awaiting his mother, and during the third like an old man. Is she sick, or with her husband? He lies on the floor, in a fever of desire and longing [...] and sits up and cries at this ghost. [...]. Soon he didn't know who he was supposed to be. (Kureishi, 1997b, pp. 136-137)"
}

The man's abandonment by the woman with whom he has an affair in "Nightlight" represents the inevitable temporariness of love affairs among the people due to the constant flux and dynamism of contemporary world. Similar to this story, Zee's interest in Eddie rather than Waldo indicates the inevitability of transformation in interpersonal relations in sexual sense. However, while Zee has a consumerist approach to her relation with her husband, Eddie also shows a similar tendency in his relations with the female characters in the novel. Waldo as both the character and the narrator of the work explains Eddie's consumerism of his sexual relations with different women in the following words:

"I explain that there are, as I've gathered from the diary, at least two other women at the moment, along with several from the past who still take an interest in him. I find ten women's names in his 'keep in touch' list. Love is consuming work. Eddie is generous with his time. He gives the women a lot of himself. [...]. I inform Anita of this."

$[\ldots]$ 


\begin{abstract}
"She begins. 'You confirm your work. The most significant is a widow called Patricia Howard. She has had a mastectomy and been alone for five years. She's keen to be loved. She is hot and wealthy, but has three grown-up children who are suspicious of Eddie and protective of their mother."

$[\ldots]$

"There's another one, Sarah Adler, twenty eight. An artist, mad as a cut snake, his favourite fuck. [...]. She has a beautiful body with delicious breasts that she likes to have pegged. She wears a pretty chain between her tits. She talks and he listens, which is unusual with men. She is dependent, and threatens suicide once a month. She sucks him off better than anyone ever has.' (Kureishi, 2017, pp. 92-94)"
\end{abstract}

In the narrator's words in "D'Accord, Baby", "infidelities would occur in most relationships. These days every man and woman was a cuckold. And why not, when marriage was insufficient to satisfy most human need?" (Kureishi, 1997a, p. 53). While consumerism leads to the constant change in people's approaches to each other and the transformations in personal relations, Hanif Kureishi elaborates on the causes of contemporary man's tendency to establish short-term relations with each other in the social area. Particularly, his following words in his short story "The Flies" can be an appropriate explanation about the reasons for the establishment of temporary relations among the people in the social context: "Surely happiness is forgetting who you are" (Kureishi, 1997c, p. 189). Forgetting who a person is signifies not only an alienation from the original individual identity which is based on a set of values and ideals, but it also represents an escapism from the anxieties and realities of the life circumstances. In The Buddha of Suburbia, Karim's following words as the narrator regarding his individual self epitomise the escapism from the problems and anxieties of contemporary social area as among the causes of forgetting oneself:

\footnotetext{
"In Europe terrorist groups were bombing capitalist targets; in London psychologists were saying you had to live your own life in your own way and not according to your family, or you'd go mad. [...]. Sometimes I felt the whole world was converging on this little room. [...]. I wanted my life to begin now, at this instant, just when I was ready for it. (Kureishi, 1990, p. 62)"
}

Bombing the capitalist targets signifies the feeling of insecurity in the social area while the suggestion to lead individual lives not based on the principles of the family embodies contemporary people's efforts for the alienation from the established social ideals. Waldo as the narrator in The Nothing names these anxieties and problematic issues in The Buddha of Suburbia as "truth" and his following arguments can be considered as an appropriate explanation concerning the reason for the contemporary people's reaction to the circumstances in the social context: "They flee the truth like Ebola" (Kureishi, 2017a, p. 95). At this point, Kureishi deals with sex as an embodiment of the contemporary man's quest for a new self in the novel. In particular, in Eddie's words, "sex is the only time I don't have anxiety, and can forget myself" (Kureishi, 2017a, p. 88). Although Eddie forgets himself by escaping from the real-life circumstances by means of sexual affairs, Waldo as the narrator reflects his critical view concerning sex as an escapism from the truth: "We have lost our relationship to truth and value and become slaves to [...] brief passions. Sex fantasies" (Kureishi, 2017a, p. 80). Man's servitude to brief passions and sex fantasies while alienating from the truth and values accounts for the temporariness of interpersonal relations while it also embodies his quest for a new self within the dynamism of contemporary circumstances.

\title{
4. Conclusion
}

Hanif Kureishi's The Nothing is a story representing the consumption of temporary sexual relations among the people as a by-product of the dynamism and constant flux in the contemporary context. Zee's affair with Eddie despite her marriage with Waldo, Eddie's 
sexual relations with Patricia Howard and Sarah Adler signify contemporary man's alienation from the traditional social systems and a quest for a new individual identity within the domination of consumerism as a major phenomenon in the twenty-first century circumstances. Waldo, Zee and Eddie's efforts for the association of their new self with sexual affairs do not supposedly contribute to the establishment of an individual identity because of the constant flux occurring in an unprecedented speed in the contemporary world. Thus, "change" characterises the contemporary lifestyle and it somehow makes it hard to maintain an identity based on a set of values and ideals and hence to establish permanent relations in the social area. In Kureishi's words, "we are our own foreigners" (Kureishi, 2017b). So, it seems difficult to predict if mankind will achieve to find their individualities and base their relations on a steady set of values and ideals within the dynamism of the twenty-first century.

\section{References}

Ahmad, A. S. \& Donnan H. (1994). Islam in the age of postmodernity. In A. S. Ahmad \& H. Donnan (Eds.), Islam, globalisation and postmodernity (pp. 1-20). London: Routledge.

Beyer, P. (1994). Religion and globalisation. London: Sage.

Boehmer, E. (2005). Colonial\&postcolonial literature ( $2^{\text {nd }}$ edition). Oxford: Oxford University Press.

Day, G. S. \& Aaker, D. (1970). A guide to consumerism. Journal of Marketing, 34 (3), pp. 12-19. Retrieved from: https://www.jstor.org/stable/1249814 .

Deonandan, R. (2002). The source of the rage: an interview with Hanif Kureishi. Retrieved from: podium.deonandan.com/an-interview-with-hanif-kureishi.html.

Hall, S. (1992). The question of cultural identity. In S. Hall, D. Held and T. McGrew (Eds.), Modernity and its futures (pp. 273-326). Cambridge: Polity.

Held, D. (2000). Introduction. In David Held (Ed.), A globalising world? Culture, economics, politics (pp. 1-6). London: Routledge.

Karner, C., \&Aldridge, A. (2004). Theorising religion in a globalising world. International Journal of Politics, Culture and Society, 18 (1), 5-32.

Kennedy, P. (2001). Introduction: globalisation and the crisis of identities?, In P. Kennedy and C. J. Danks (Eds.), Globalisation and national identities: crisis or opportunity? (pp. 1-28) Hampshire: Palgrave.

Kureishi, H. (1990). The buddha of suburbia. London: Faber \& Faber.

Kureishi, H. (1997a). D'accord baby. In Collected stories (pp. 51-59). London: Faber \& Faber.

Kureishi, H. (1997b). Nightlight. In Collected stories (pp. 134-140). London: Faber \& Faber.

Kureishi, H. (1997c). Lately. In Collected stories (pp. 141-180). London: Faber \& Faber.

Kureishi, H. (1997d). The flies. In Collected stories (pp. 18-204). London: Faber \& Faber.

Kureishi, H. (1999). The umbrella. In Collected stories (pp. 338-347). London: Faber \& Faber.

Kureishi, H. (2017a). The nothing. London: Faber \& Faber.

Kureishi, H. [Hanifkureishi]. (2017b, March 23). We are our own foreigners [Tweet]. Retrieved from: https://www.twitter.com/Hanifkureishi/status/844857347407163392?p=v 
Lu, F. (2010). On consumerism and 'the logic of capital'. In Q. Huan (Ed.), Eco-socialism as politics: rebuilding the basis of our civilisation (pp. 77-102). London: Springer.

Mason, D. (2008). The secret vice: masturbation in Victorian fiction and medical culture. Manchester: Manchester University Press.

Noddings, N. (1989). Women and evil. California: University of California Press.

O'Gorman, D. (2013). 'The journey creates us. We become the frontiers we cross': Stepping across lines in Salman Rushdie's Shalimar the Clown. In S. Adiseshiah \& R. Hildyard (Eds.), Twenty-first century fiction: what happens now (pp. 81-96). Hampshire: Palgrave Macmillan.

Rushdie, S. (2015). Two years, eight months and twenty eight nights. London: Jonathan Cape.

Shamsie, K. (2017). Home fire. London: Bloomsbury.

Smith, Z. (2005). On beauty. London: Penguin Books.

Smith, Z. (2013). NW ( $2^{\text {nd }}$ edition). London: Penguin Books.

Smith, Z. (2017). Swing time ( $2^{\text {nd }}$ edition). London: Penguin Books. 